\title{
High-Normal Arterial Blood Pressure in Children With Excess Body Weight
}

\author{
Malgorzata Kolpa, ${ }^{1}$ Agnieszka Jankowicz-Szymanska, ${ }^{1}$ and Beata Jurkiewicz, ${ }^{1,}$ \\ ${ }^{1}$ Institute of Health Sciences, State Higher Vocational School in Tarnow, Poland \\ "Corresponding author: Beata Jurkiewicz, Institute of Health Sciences, State Higher Vocational School in Tarnow, Poland. Tel: +48-1463116510, Fax: +48-14631510571, E-mail: \\ beatajurkiewicz@interia.pl
}

Received 2015 November 11; Revised 2016 February 14; Accepted 2016 March 09.

\begin{abstract}
Background: Childhood overweight and obesity are common causes of metabolic disorders that persist until adulthood. Objectives: The purpose of this study was to determine the prevalence of high-normal arterial blood pressure (ABP) in children with excess body weight.

Material and Methods: A total of 1,093 schoolchildren aged 10 - 12 years (51\% girls and $49 \%$ boys) participated in the study. The children's weight, height, body fat percentage (BFP), waist and hip circumference, and ABP were measured. The waist-to-height ratio (WHtR) and body mass index (BMI) were calculated and compared to the normative reference values accepted by the International obesity task force (IOTF).

Results: Excess weight was identified in $20 \%$ of the participants, and obesity in $5 \%$. A total of $35.5 \%$ of overweight children had abovenormal ABP, which implied hypertension. In obese children, that proportion equaled 59.3\%. BFP was 6.5\% greater in children with hypertension than in those with normal BP. The children with hypertension also had a 7.6-cm larger waist circumference, a 7.6-cm larger hip circumference, and a greater WHtR (by 0.04).

Conclusions: Excess body weight was identified in 25\% of children aged 10 - 12 years, significantly increasing their risk of developing hypertension.
\end{abstract}

Keywords: Arterial Blood Pressure, Overweight, Obesity, School Age

\section{Background}

The academic literature contains increasing numbers of reports on the global obesity epidemic. Poland has joined the group of countries in which the growing issue of childhood obesity requires immediate action. Throughout the world, more than 22 million children under 5 years of age are overweight, and approximately $10 \%$ of those aged 5 - 17 years are either overweight or obese (1). In 2012, the problem of excess body weight affected over 30\% of children and adolescents in the United States (2). In the European Union, overweight and obesity are recognized in $25 \%$ of children. In Poland in 2009, excess body weight was identified in $16.4 \%$ of children and adolescents aged 6 - 19 years (3).

Nutritional and metabolic disorders in children and adolescents mainly result from improper lifestyle (due to the preferred passive forms of relaxation) and poor eating habits $(4,5)$. Excess body weight is regarded as a factor in the development of metabolic disorders, such as cardiovascular disease, arterial hypertension, disturbed lipid and carbohydrate metabolism (including type 2 diabetes), and, most of all, a greater risk of obesity and obesity-related health problems in adulthood $(6,7)$. The joint prevalence of lipid/carbohydrate metabolism disorders and hypertension resulting from obesity and insulin resistance (IR) is known as metabolic syndrome, and was first described by Reaven in 1988 (8).

At least one element of metabolic syndrome is found in two thirds of overweight or obese adolescents, and the complete syndrome can be recognized in almost a third (9). It should be emphasized that $80 \%$ of children with metabolic syndrome are overweight (10). In children, as in adults, there is a strong link between obesity and hypertension. In 1995, Chen et al. presented study findings confirming that childhood obesity affects systolic arterial blood pressure (11).

Both the prevention and the early recognition and treatment of metabolic syndrome are important due to the direct connection between metabolic syndrome and a distinctly increased risk of cardiovascular disease.

\section{Objectives}

The purpose of this study was to determine the prevalence of high-normal arterial blood pressure $(\mathrm{ABP})$ in chil- 
dren with excess body weight.

\section{Materials and Methods}

\subsection{Study Design and Participants}

The survey was conducted from September to December 2014 in Tarnow (Malopolska Region, Poland). Primary schools were randomly selected, and a total of 1,093 schoolchildren aged 10 - 12 years, including 556 girls (51.0\%) and 537 boys (49.0\%), participated in the study. The mean age of the participants was $11.04 \pm 0.83$ years for girls and $11.01 \pm 0.81$ years for boys. The precise numbers of participants in the various age groups are presented in Table 1. The participants took part in the project after written informed consent was obtained from their parents/legal guardians. Those with certified disabilities or who were being treated for chronic diseases were excluded from the study. The consent of the local bioethics committee was obtained prior to conducting the study.

Table 1. Number of Participating Girls and Boys According to Age

\begin{tabular}{llcc}
\hline Age/Gender & Number of Participants & Total, \% \\
\hline $\mathbf{1 0}$ & & 182 & 16.65 \\
\hline $\mathbf{1 1}$ & Girls & 177 & 16.19 \\
\hline & Goys & 167 & \\
\hline $\mathbf{1 2}$ & Boys & 177 & 15.28 \\
& Girls & & 16.19 \\
\hline & Boys & 207 & 18.94 \\
\hline All & & 183 & 16.74 \\
\hline & Girls & & 49.13 \\
\hline & Boys & 556 & 50.87 \\
\hline
\end{tabular}

\subsection{Data Collection}

Measurements were conducted in a well-lit and warm room. The same sequence of measurements was maintained and the same equipment, operated by the same individuals, was used. The participants were measured in their underclothes, with no footwear. Height was measured with a calibrated anthropometer to within $0.01 \mathrm{~m}$, from the floor to the skull vertex, as the participants stood in the erect position with feet together and looking straight ahead.

Body weight was measured on Tanita BR-350 scales to within $0.1 \mathrm{~kg}$. The same equipment was used to assess body fat percentage (BFP) using foot-to-foot bioelectrical impedance analysis (BIA) technology. Body mass index (BMI) was calculated based on height and weight, using the Cole and Bellizzi standards (accepted by the international obesity task force). Each participant was classified into one of three groups: healthy weight, overweight, or obese (Table 2) (12).

The arterial blood measurements were conducted using the auscultatory method based on Korotkoff sounds. The Hi-End Accoson Greenlight 300 sphygmomanometer was used. Systolic blood pressure (SBP) was recorded at the appearance of Korotkoff sounds (phase I), and diastolic blood pressure (DBP) was recorded at the muffling of sounds (phase IV) (13). The principles of proper preparation for measurements were maintained by the participants. The results of BP, after taking into account gender, age, and height, were compared to BP tables for children and adolescents as elaborated by American experts. Prehypertension in children is defined as average SBP or DBP levels greater than or equal to the 9oth percentile, but less than the 95th percentile. Hypertension is defined as average SBP and/or DBP levels greater than or equal to the 95th percentile for sex, age, and height (14). Hypertension would have been recognized if high-normal ABP had been revealed during several examinations within a few week or several months, hence in such cases, only suspected arterial hypertension could be taken into account. When ABP equaled at least the 9oth percentile, the measurement was repeated and the mean values for SBP and DBP were calculated. The results were categorized into the following groups: normal BP, high-normal BP, or hypertension.

\subsection{Data Analysis}

The analysis of the results was conducted using basic descriptive statistics: mean, median, minimum and maximum values, and standard deviations. The normality of distribution was assessed by means of the Shapiro-Wilk test (if the value of the Shapiro-Wilk test was $>0.05$, the data was normal). Because the data was not normally distributed $(\mathrm{P}<0.05)$, the significance of intergroup differences was assessed with non-parametric tests: the MannWhitney U test (for two groups) or the Kruskal-Wallis and post-hoc Tukey test (for three groups). The level of significance was accepted at $\mathrm{P}=0.05$. Statistical analyses were performed using SPSS 20.0.

\section{Results}

\subsection{Comparison of Results Between Boys and Girls}

Boys and girls did not differ significantly in height, weight, and BMI. The girls had a $4.8 \%$ greater BFP. The girls' 
Table 2. International Cut-Off Points for BMI for Overweight and Obesity by Sex Between 10 and 12 Years (12)

\begin{tabular}{|c|c|c|c|c|}
\hline \multirow[t]{2}{*}{ Age, $y$} & \multicolumn{2}{|c|}{$\mathrm{BMI} \geq 25, \mathrm{~kg} / \mathrm{m}^{2}$} & \multicolumn{2}{|c|}{$\mathrm{BMI} \geq 30 \mathrm{~kg} / \mathrm{m}^{2}$} \\
\hline & Males & Females & Males & Females \\
\hline 10 & 19.84 & 19.86 & 24.00 & 24.11 \\
\hline 10.5 & 20.20 & 20.29 & 24.57 & 24.77 \\
\hline 11 & 20.55 & 20.74 & 25.10 & 25.42 \\
\hline 11.5 & 20.89 & 21.20 & 25.58 & 26.05 \\
\hline 12 & 21.22 & 21.68 & 26.02 & 26.67 \\
\hline
\end{tabular}

waist circumference was $3 \mathrm{~cm}$ smaller than that of the boys, whereas hip circumference was $5.5 \mathrm{~cm}$ greater in the girls; however, this difference was not of statistical significance. It was determined that the WHtR was considerably smaller in girls. Gender did not strongly correlate with SBP and DBP (Table 3).

\subsection{Comparison of Participants With Normal and High $A B P$}

Normal ABP prevailed in 764 (70.0\%) of the participants, high-normal BP was identified in 130 (11.8\%), and hypertension was found in 199 (18.2\%). Seventy-two percent of the girls and $68.0 \%$ of the boys had normal BP, while hypertension was found in $16.0 \%$ of the girls and 20.3\% of the boys. Participants with normal ABP were considerably shorter and lighter, and had significantly lower BMI than their age-mates with high-normal and normal BP. There were similar findings with regard to BFP, which was $4.6 \%$ greater in participants with high-normal BP and $6.5 \%$ greater in those with hypertension than in participants with normal BP. Children with high-normal BP and those with hypertension also had greater waist circumferences (5.0 and $7.6 \mathrm{~cm}$ greater, respectively), hip circumferences ( 6.0 and $7.6 \mathrm{~cm}$ greater, respectively), and WHtR(0.02 and 0.04 points greater, respectively) than their age-mates with normal BP.

\subsection{Comparison of Participants With Healthy and Excess Body Weight}

Healthy weights were found more frequently in boys than in girls (78.2\% and $71.8 \%$, respectively). Excess body weight was found in $20.6 \%$ of girls and $19.2 \%$ of boys, and obesity in $7.5 \%$ of girls and $2.5 \%$ of boys. In total, excess weight was identified in 218 (20.0\%) participants, with obesity in 54 (5.0\%). Weight status differentiated all of the variables under investigation. BFP was $10.4 \%$ greater in children with excess body weight and $16.0 \%$ greater in obese children than in healthy-weight participants. The obese children's waist circumference was $10.3 \mathrm{~cm}$ larger and hip circumference was $9.1 \mathrm{~cm}$ larger than in the non-obese overweight children, and $22.2 \mathrm{~cm}$ and $20.1 \mathrm{~cm}$ larger, respectively, than in children with healthy weight. In the healthy-weight children, normal BP was identified in 78.0\%, high-normal BP in $10.0 \%$, and hypertension in $12.0 \%$. In the participants with excess weight, those values were $47.7 \%$, $16.8 \%$, and $35.5 \%$, respectively, and in obese participants they were $18.5 \%, 22.2 \%$, and $59.3 \%$, respectively.

\section{Discussion}

Excess body weight was identified in $20.0 \%$ of the participants in this study, and obesity in $5.0 \%$. Similar proportions were reported by researchers in Greece, who found excess weight and obesity in $22.4 \%$ and $6.5 \%$ of their participants, respectively (15). They also noted that excess body weight was more common in boys than in girls. The present study did not reveal statistically significant differences in BMI between boys and girls. On the other hand, a group of researchers from Saudi Arabia found distinctly higher BMI values in girls (16). The same researchers discovered that it was typical of boys to have greater BFP than girls, which was also confirmed by the findings of our study. Bacopoulou et al. revealed that boys had higher values than girls for waist and hip circumference and for WHtR (17). These differences with our study are due to the fact that in our research, the girls had greater hip circumference than the boys.

In the Bogalus Heart Study, one of the largest epidemiological investigations into the incidence of arterial hypertension in young populations, arterial hypertension was found in $7.0 \%$ of participants (18). In the Lande and Flynn research, chronic arterial hypertension was discovered in $11.0 \%$ of children (19). In our study, values indicating arterial hypertension were revealed in $18.2 \%$ of children. According to the academic data, arterial hypertension is 3 - 5 times more common in obese children than in their healthy-weight age-mates (20). Janus et al. revealed a high correlation between the prevalence of obesity and arterial hypertension (21). Moselakgomo et al. found a posi- 
Table 3. Comparison of Selected Variables in Gender Groups (Mann-Whitney U Test, $P=0.05$ )

\begin{tabular}{|c|c|c|c|c|c|c|}
\hline Variable/Gender & Mean & Median & Min & Max & SD & P Value \\
\hline Height, $\mathrm{cm}$ & & & & & & 0.9 \\
\hline Girls & 148.85 & 148.60 & 126.80 & 176.60 & 8.99 & \\
\hline Boys & 149.13 & 148.20 & 123.60 & 174.50 & 9.30 & \\
\hline Weight, kg & & & & & & 0.7 \\
\hline Girls & 41.60 & 40.50 & 22.20 & 70.20 & 9.85 & \\
\hline Boys & 42.72 & 40.10 & 23.70 & 107.80 & 12.32 & \\
\hline BMI, $\mathrm{kg} / \mathrm{m}^{2}$ & & & & & & 0.8 \\
\hline Girls & 18.58 & 18.04 & 12.80 & 28.41 & 3.11 & \\
\hline Boys & 18.95 & 17.90 & 12.80 & 39.20 & 3.91 & \\
\hline \% Fat & & & & & & $<0.001^{\mathrm{a}}$ \\
\hline Girls & 22.08 & 21.80 & 5.00 & 40.20 & 6.93 & \\
\hline Boys & 17.32 & 15.40 & 5.00 & 44.70 & 7.59 & \\
\hline Waist circumference, $\mathrm{cm}$ & & & & & & $<0.001^{\mathrm{a}}$ \\
\hline Girls & 62.69 & 62.00 & 48.40 & 93.00 & 7.29 & \\
\hline Boys & 65.69 & 63.70 & 12.60 & 115.00 & 9.62 & \\
\hline Hip circumference, $\mathrm{cm}$ & & & & & & 0.05 \\
\hline Girls & 81.02 & 81.05 & 22.40 & 106.00 & 8.83 & \\
\hline Boys & 80.47 & 79.40 & 54.00 & 124.30 & 9.66 & \\
\hline WHtR & & & & & & $<0.001^{\mathrm{a}}$ \\
\hline Girls & 0.42 & 0.41 & 0.33 & 0.60 & 0.04 & \\
\hline Boys & 0.44 & 0.43 & 0.08 & 0.71 & 0.05 & \\
\hline Systolic blood pressure, $\mathrm{mmHg}$ & & & & & & 0.9 \\
\hline Girls & 107.32 & 110.00 & 70.00 & 174.00 & 14.49 & \\
\hline Boys & 107.49 & 110.00 & 70.00 & 170.00 & 14.16 & \\
\hline Diastolic blood pressure, $\mathrm{mmHg}$ & & & & & & 0.4 \\
\hline Girls & 66.21 & 65.00 & 40.00 & 141.00 & 10.28 & \\
\hline Boys & 66.96 & 70.00 & 40.00 & 144.00 & 10.10 & \\
\hline
\end{tabular}

${ }^{\mathrm{a}}$ Statistically significant difference.

tive correlation between systolic and diastolic blood pressure, weight, and BFP (22). This was also confirmed in our study. Children with excess weight and obesity had high-normal ABP significantly more often than those with healthy weights, and BFP was also greater in children with high-normal ABP.

Rutkowski et al. confirmed the joint prevalence of high-normal ABP and greater WHtR, and identified a correlation between obesity and arterial hypertension; this was found significantly more often in participants with a greater WHtR (23).

Bakeri et al. were the first to show a significant correlation between high BMI in childhood and the incidence of coronary disease and higher mortality due to cardiac problems in adulthood (24). Moreover, other studies have revealed the distant consequences of obesity, such as disturbed carbohydrate metabolism or the development of circulatory diseases in adulthood, even when it was possible for the obese child to attain a normal weight before maturity (25-27).

\subsection{Conclusions}

1) Excess body weight was identified in $28 \%$ of girls and $22 \%$ of boys aged $10-12$ years.

2) Overweight and obesity increased the risk of highnormal ABP in schoolchildren. 


\subsection{Implications for Practice}

In light of these findings, all possible steps should be taken to identify arterial hypertension in school-aged children, and preventive measures against overweight and obesity should be implemented for these children. Regular blood pressure control is an essential part of medical care for children with excess body weight.

\section{Footnote}

Authors' Contribution: Malgorzata Kolpa: study concept and design, analysis and interpretation of data, critical revision of the manuscript for important intellectual content, statistical analysis, administrative, technical, and material support, and study supervision; Agnieszka Jankowicz-Szymanska: acquisition of data, analysis and interpretation of data, statistical analysis, and study supervision; Beata Jurkiewicz: analysis and interpretation of data, drafting of the manuscript, and study supervision.

\section{References}

1. Kosti RI, Panagiotakos DB. The epidemic of obesity in children and adolescents in the world. Cent Eur J Public Health. 2006;14(4):151-9. [PubMed: 17243492].

2. Ogden CL, Carroll MD, Kit BK, Flegal KM. Prevalence of childhood and adult obesity in the United States, 2011-2012. JAMA. 2014;311(8):806-14. doi: 10.1001/jama.2014.732. [PubMed: 24570244].

3. Grajda A, Kulaga Z, Gurzkowska B, Napieralska E, Litwin M. Regional differences in the prevalence of overweight, obesity and underweight among polish children and adolescents. Med Wieku Rozwoj. 2011;15(3):258-65. [PubMed: 22006473].

4. Vilchis-Gil J, Galvan-Portillo M, Klunder-Klunder M, Cruz M, FloresHuerta S. Food habits, physical activities and sedentary lifestyles of eutrophic and obese school children: a case-control study. BMC Public Health. 2015;15:124. doi: 10.1186/s12889-015-1491-1. [PubMed: 25885348].

5. Galson SK. Childhood overweight and obesity prevention. Public Health Rep. 2008;123(3):258-9. [PubMed: 19006963].

6. Nguyen NT, Magno CP, Lane KT, Hinojosa MW, Lane JS. Association of hypertension, diabetes, dyslipidemia, and metabolic syndrome with obesity: findings from the National Health and Nutrition Examination Survey, 1999 to 2004. J Am Coll Surg. 2008;207(6):928-34. doi: 10.1016/j.jamcollsurg.2008.08.022. [PubMed: 19183541].

7. Freedman DS, Mei Z, Srinivasan SR, Berenson GS, Dietz WH. Cardiovascular risk factors and excess adiposity among overweight children and adolescents: the Bogalusa Heart Study.J Pediatr. 2007;150(1):12-17 e2. doi: 10.1016/j.jpeds.2006.08.042. [PubMed: 17188605].

8. Reaven GM. Banting lecture 1988. Role of insulin resistance in human disease. Diabetes. 1988;37(12):1595-607. [PubMed: 3056758].

9. de Ferranti SD, Gauvreau K, Ludwig DS, Neufeld EJ, Newburger JW, Rifai N. Prevalence of the metabolic syndrome in American adolescents: findings from the Third National Health and Nutrition Examination Survey. Circulation. 2004;110(16):2494-7. doi: 10.1161/01.CIR.0000145117.40114.C7. [PubMed:15477412].

10. Cook S, Weitzman M, Auinger P, Nguyen M, Dietz WH. Prevalence of a metabolic syndrome phenotype in adolescents: findings from the third National Health and Nutrition Examination Survey, 19881994. Arch Pediatr Adolesc Med. 2003;157(8):821-7. doi: 10.1001/archpedi.157.8.821. [PubMed: 12912790].
11. Chen Y, Rennie DC, Reeder BA. Age-related association between body mass index and blood pressure: the Humboldt Study. Int J Obes Relat Metab Disord. 1995;19(11):825-31. [PubMed: 8589786].

12. Cole TJ, Bellizzi MC, Flegal KM, Dietz WH. Establishing a standard definition for child overweight and obesity worldwide: international survey. BMJ. 2000;320(7244):1240-3. [PubMed:10797032].

13. Perloff D, Grim C, Flack J, Frohlich ED, Hill M, McDonald M, et al. Human blood pressure determination by sphygmomanometry. Circulation. 1993;88(5 Pt 1):2460-70. [PubMed: 8222141].

14. National High Blood Pressure Education Program Working Group on High Blood Pressure in C. The fourth report on the diagnosis, evaluation, and treatment of high blood pressure in children and adolescents. Pediatrics. 2004;114(2 Suppl 4th Report):555-76. [PubMed: 15286277].

15. Al-Mohaimeed A, Ahmed S, Dandash K, Ismail MS, Saquib N. Concordance of obesity classification between body mass index and percent body fat among school children in Saudi Arabia. BMC Pediatr. 2015;15:16. doi: 10.1186/s12887-015-0335-6. [PubMed: 25879922].

16. Christoforidis A, Dimitriadou M, Papadopolou E, Stilpnopoulou D, Katzos G, Athanassiou-Metaxa M. Defining overweight and obesity among Greek children living in Thessaloniki: International versus local reference standards. Hippokratia. 2011;15(2):141-6. [PubMed: 22110296].

17. Bacopoulou F, Efthymiou V, Landis G, Rentoumis A, Chrousos GP. Waist circumference, waist-to-hip ratio and waist-to-height ratio reference percentiles for abdominal obesity among Greek adolescents. BMC Pediatr. 2015;15:50. doi: 10.1186/s12887-015-0366-z. [PubMed: 25935716].

18. Alper AJ, Chen W, Yau L, Srinivasan SR, Berenson GS, Hamm LL. Childhood uric acid predicts adult blood pressure: the Bogalusa Heart Study. Hypertension. 2005;45(1):34-8. doi: 10.1161/01.HYP.0000150783.79172.bb. [PubMed:15569853].

19. Lande MB, Flynn JT. Treatment of hypertension in children and adolescents. Pediatr Nephrol. 2009;24(10):1939-49. doi: 10.1007/s00467007-0573-4. [PubMed: 17690916].

20. Feld LG, Corey H. Hypertension in childhood. Pediatr Rev. 2007;28(8):283.

21. Janus D, Wojcik M, Kalicka-Kasperczyk A, Maslanka A, Radwanska M, Olchawa-Czech A, et al. [Hypertension in obese children and adolescents]. Przegl Lek. 2013;70(1):6-10. [PubMed: 23789297].

22. Moselakgomo VK, Toriola AL, Shaw BS, Goon DT, Akinyemi O. Body mass index, overweight, and blood pressure among adolescent schoolchildren in Limpopo province, South Africa. Revista Paulista de Pediatria. 2012;30(4):562-9.

23. Rutkowski B, Czarniak P, Krol E, Szczesniak P, Zdrojewski T. Overweight, obesity, hypertension and albuminuria in Polish adolescents-results of the Sopkard 15 study. Nephrol Dial Transplant. 2013;28 Suppl 4:iv204-11. doi: 10.1093/ndt/gft328. [PubMed: 24068778].

24. Baker JL, Olsen LW, Sorensen TI. Childhood body-mass index and the risk of coronary heart disease in adulthood. $N$ Engl J Med. 2007;357(23):2329-37. doi: 10.1056/NEJMoa072515. [PubMed: 18057335].

25. Jones KL. The dilemma of the metabolic syndrome in children and adolescents: disease or distraction?. Pediatr Diabetes. 2006;7(6):311-21. doi: 10.1111/j.1399-5448.2006.00212.x. [PubMed: 17212598].

26. Must A, Jacques PF, Dallal GE, Bajema CJ, Dietz WH. Long-term morbidity and mortality of overweight adolescents. A follow-up of the Harvard Growth Study of 1922 to 1935. N Engl J Med. 1992;327(19):1350-5. doi: 10.1056/NEJM199211053271904. [PubMed: 1406836].

27. Schillaci G, Pirro M, Vaudo G, Gemelli F, Marchesi S, Porcellati $\mathrm{C}$, et al. Prognostic value of the metabolic syndrome in essential hypertension. J Am Coll Cardiol. 2004;43(10):1817-22. doi: 10.1016/j.jacc.2003.12.049. [PubMed: 15145106]. 